\title{
Transperitoneal laparoscopic nephrectomy: Assessing complication risk in cases of previous abdominal surgery
}

\author{
Simon Ouellet, MD; Robert Sabbagh, MD, MSc, FRCSC; Claudio Jeldres, MD, MSc, FRCSC \\ Division of Urology, Departments of Surgery, Centre Hospitalier Universitaire de Sherbrooke, Université de Sherbrooke, Sherbrooke, QC, Canada
}

Cite as: Can Urol Assoc J 2017;11(3-4):131-5. http://dx.doi.org/10.5489/cuaj.4107

\section{Abstract}

Introduction: We aimed to assess the effect of previous abdominal surgery on perioperative outcomes in patients undergoing transperitoneal laparoscopic partial (LPN) or radical (LRN) nephrectomy for renal masses.

Methods: We retrospectively reviewed all cases of LPN and LRN for renal masses at our institution between 2008 and 2014. Patients were divided in two groups, those with and without prior abdominal surgery. Four perioperative outcomes were compared, namely, operative time (OT), estimated blood loss (EBL), length of stay (LOS), and 30-days complications rate. A subanalysis was performed to address the impact of previous open cholecystectomy on right LPN or LRN.

Results: Of 293 patients identified, 146 (49.8\%) had previous abdominal surgery. In univariate analysis, no differences in operative time (136 vs. 144 minutes; $p=0.154), E B L(88$ vs. $100 \mathrm{~mL}$; $\mathrm{p}=0.211$ ), or 30 -day complication rate ( 24 vs. $14 \% ; p=0.069)$ were recorded between the groups. Only LOS favoured patients without previous abdominal surgery ( 3 vs. 4 days; $p=0.001$ ). In multivariate analysis, prior abdominal surgery was not associated with an increased OT, EBL, LOS, or complication rate. The analysis of right nephrectomies showed increased OT (148 vs. $128 \mathrm{~min}$ utes; $p=0.049$ ) and complication rate (42 vs. $16 \% ; p=0.004)$ for patients with past open cholecystectomy compared to those without. Multivariate analysis revealed that prior open cholecystectomy was associated with a longer $\operatorname{LOS}\left(\mathrm{OR}_{\text {median }}=2.7[1.2-8.0]\right)$ and an increased risk of complications $\left(\mathrm{OR}_{\text {median }}=4.5\right.$ [1.6-10.5]).

Conclusions: In this cohort, previous abdominal surgery was not associated with worse perioperative outcomes after transperitoneal LPN and LRN for renal masses. However, previous open cholecystectomy resulted in a higher risk of complication and a longer LOS in patients undergoing right laparoscopic nephrectomy.

\section{Introduction}

Previous abdominal surgery is a known risk factor for the development of intra-abdominal adhesions and can develop in more than $90 \%$ of patients with a history of major abdominal surgery. ${ }^{1,2}$ Adhesions can increase perioperative complications and prolongs operative time. - $^{3-5}$ Previous open abdominal surgery results in increased hospital length of stay (LOS), complication rate, and operation time (OT) in patients undergoing subsequent laparoscopic general surgery. ${ }^{6}$ Previous abdominal surgery also results in more access-related complications in laparoscopic gynecological procedures.

Patient with renal masses, especially those with small renal tumours are currently more often treated with minimally invasive surgical techniques. ${ }^{8}$ The laparoscopic nephrectomy has been associated with shorter LOS and lower estimated blood loss (EBL) with similar complication rate when compared with open nephrectomy. ${ }^{9-11}$ To date, few studies have addressed the effect of past abdominal surgery on urological laparoscopy and results are conflicting. ${ }^{12-16}$ We hypothesized that previous intraperitoneal surgery may have a detrimental effect. Therefore, we evaluated the effect of previous abdominal surgery on operative and perioperative outcomes in adult patients undergoing transperitoneal laparoscopic partial (LPN) or radical (LRN) nephrectomy for renal masses.

\section{Methods}

\section{Patient cohort}

Both the internal review board and ethics committee approved the study for retrospective chart review of all adult patients who underwent LPN or LRN at our institution between 2008 and 2014. Only cases performed for renal masses without synchronous surgery were included. We stratified the 293 patients into two groups: those with and those without prior abdominal surgery. This population is part of a provincial public health system, where our institution is the only tertiary care referral centre; therefore, virtually all the medical/surgical history of these patients was recorded in our charts. Moreover, if any patients would 
have been subjected to a surgery at another institution before being treated at our institution, it should be properly recorded in the chart by the treating physician, the preoperative checklist, and/or the anesthesia perioperative evaluation. All procedures were pure laparoscopic nephrectomies and were performed by two experienced laparoscopic surgeons.

Patient characteristics included age, sex, American Society of Anesthesiologists (ASA) score, Charlson Comorbidity Index $(\mathrm{CCl})$, body mass index (BMI), and past surgical history. Previous abdominal surgery was defined as any open or laparoscopic procedure that entered the peritoneal cavity. Endoscopic procedures and inguinal surgeries were not considered in the abdominal surgery group. Pathological features recorded included pathological stage (2010 TNM classification), as well as tumour size and localization. Operative and perioperative data were compared between the two groups, namely, EBL (in $\mathrm{mL}$ ), OT (in minutes), LOS (in days), and 30-day complications (Clavien classification).

\section{Statistics}

Categorical variables were compared with Chi-square or Fisher's exact tests. Continuous variables were analyzed with Student's t-tests and Mann-Whitney U tests. Logistic regression analysis was used to determine whether previous abdominal surgery was associated with complications or worse perioperative outcomes. These outcomes were defined as results inferior to the whole cohort's median (i.e., EBL $\geq 100 \mathrm{~mL}$, OT $\geq 135$ minutes, and LOS $\geq 4$ days). IBM SPSS Statistics for Windows, Version 22.0 was used for statistical analysis (released 2013, IBM Corp Armonk, NY, U.S.) and all tests were two-sided, with a significance level set at $p<0.05$.

\section{Results}

Of the 293 patients who met our inclusion criteria, 146 $(49.8 \%)$ had a history of abdominal surgery (Table 1$)$. Table 2 lists socio-demographic data and tumour characteristics. Previous abdominal surgery was associated with increased age (66.9 vs. 61.2 years; $p<0.001)$, female gender $(59.6$ vs. $19.0 \% ; \mathrm{p}<0.001)$, higher $\mathrm{CCl}(3.3$ vs. $2.6 ; \mathrm{p}=0.002)$, smaller tumours size ( 4.7 vs. $5.4 \mathrm{~cm} ; \mathrm{p}=0.048)$, and lower pathological T stage (T1a/b 73.2 vs. $60.6 \% ; \mathrm{p}=0.046)$. There were no statistically significant differences between the two groups for BMI, ASA score, tumour side and localization, type of surgery (LPN vs. LRN), or margin status.

Perioperative outcomes are shown in Table 3. Patients with previous abdominal surgery experienced increased LOS ( 4 vs. 3 days; $p=0.001$ ). However, no statistically significant difference were found in EBL (88 vs. $100 \mathrm{~mL} ; p=0.211$ ), OT (136 vs. 144 minutes; $p=0.154$ ), warm ischemia time (WIT) (21.8 vs. 22.5 minutes; $p$ 0.635), rate of conversion to open surgery ( 2.1 vs. $1.4 \% ; p=0.684)$ and rate of 30 -day complica-

\begin{tabular}{lc}
\hline Table 1. Type of previous abdominal surgery & \\
\hline Previous abdominal surgery (n=146) & $\mathbf{n}(\%)$ \\
\hline Appendectomy & $68(47)$ \\
Abdominal hysterectomy & $52(36)$ \\
Cholecystectomy & $46(32)$ \\
Tubal ligation & $13(9)$ \\
Partial colectomy & $13(9)$ \\
Caesarean section & $8(5)$ \\
Bilateral oophorectomy & $4(3)$ \\
Total colectomy and end ileostomy, open & $3(2)$ \\
Small bowel resection, open & $3(2)$ \\
Radical nephrectomy, open & $2(1)$ \\
Abdominal abscess drainage, open & $2(1)$ \\
Retroperitoneal lymph node dissection, open & $1(1)$ \\
Partial nephrectomy (ipsilateral), laparoscopic & $1(1)$ \\
Vagotomy, open & $1(1)$ \\
Abdominal aortic aneurysm repair, open & $1(1)$ \\
Heller myotomy, open & $1(1)$ \\
splenectomy (contralateral), open & $1(1)$ \\
\hline 1 procedure: 86 patients; 2 or more procedures: 60 patients. \\
\hline
\end{tabular}

tions ( 24.0 vs. $13.6 \%$; $p=0.069$ ). In multivariate analysis, prior abdominal surgery was not associated with an increased OT, $\mathrm{EBL}, \mathrm{LOS}$, or complication rate (data not shown).

Cholecystectomy was the most common previous surgery performed near the renal fossa. A subset analysis was performed to determine the impact of previous cholecystectomy on right LPN and LRN (Table 4). A total of 144 patients underwent a right LPN or LRN. Patients with $(n=19)$ and without $(n=123)$ a history of previous open cholecystectomy were compared. Two patients with prior laparoscopic cholecystectomy were excluded from this analysis. Age, BMI, ASA score, and use of nephron-sparing surgery were similar in the two groups. There were no differences in EBL, OT, WIT, or rate of conversion to open surgery. However, OT (148 vs. 128 minutes; $p=0.049$ ), LOS (4 vs. 3 days; $\mathrm{p}=0.050)$; and postoperative complication rate (42.1 vs. $16.3 \% ; p=0.004$ ) were greater in patients with vs. those without previous open cholecystectomy. In multivariate analysis, prior open cholecystectomy was associated with longer $\mathrm{LOS}\left(\mathrm{OR}_{\text {median }}=2.7[1.2-8.0]\right)$ and an increased risk of complications $\left(\mathrm{OR}_{\text {median }}=4.5\right.$ [1.6-10.5]) (data not shown). However, prior open cholecystectomy was not associated with an increased OT and EBL.

\section{Discussion}

Abdominal surgery almost always leads to some degree of intra-abdominal adhesions. ${ }^{1-2}$ Adhesions can increase perioperative risk and have already been considered a relative contraindication to laparoscopy. ${ }^{3-5}$ In our study, half of the patients had a history of previous abdominal surgery highlighting the importance of this issue. 


\begin{tabular}{|c|c|c|c|}
\hline Variables & $\begin{array}{c}\text { Past } \\
\text { abdominal } \\
\text { surgeries } \\
\text { (n=146) }\end{array}$ & $\begin{array}{c}\text { No abdominal } \\
\text { surgery } \\
(n=147)\end{array}$ & $\mathbf{p}$ \\
\hline Age, years (SD) & $66.9(11.6)$ & $61.2(12.6)$ & $<0.001$ \\
\hline Male, n (\%) & $59(40.4)$ & $119(81.0)$ & $<0.001$ \\
\hline Charlson score (SD) & $3.3(2.0)$ & $2.6(2.0)$ & 0.002 \\
\hline $\mathrm{BMI}, \mathrm{kg} / \mathrm{m}^{2}$ (SD) & $28.4(5.6)$ & $27.9(5.1)$ & 0.402 \\
\hline $\begin{array}{l}\text { ASA, n (\%) } \\
1 \\
2 \\
3 \\
4\end{array}$ & $\begin{array}{c}7(4.8) \\
88(60.7) \\
48(33.1) \\
2(1.4)\end{array}$ & $\begin{array}{c}11(7.5) \\
96(65.3) \\
39(26.5) \\
1(0.7)\end{array}$ & 0.520 \\
\hline $\begin{array}{l}\text { Right side tumour, } \\
\mathrm{n}(\%)\end{array}$ & $75(51.4)$ & $69(46.9)$ & 0.484 \\
\hline $\begin{array}{l}\text { Partial nephrectomy, } \\
\mathrm{n}(\%)\end{array}$ & $48(32.9)$ & $57(38.8)$ & 0.330 \\
\hline Tumour size cm, (SD) & $4.7(2.5)$ & $5.4(3.4)$ & 0.048 \\
\hline $\begin{array}{l}\text { Tumour localization, } \mathrm{n} \\
\text { Upper pole } \\
\text { Inter-polar pole } \\
\text { Lower pole } \\
\text { Hilar }\end{array}$ & $\begin{array}{c}43 \\
44 \\
51 \\
8\end{array}$ & $\begin{array}{c}50 \\
45 \\
44 \\
8\end{array}$ & 0.805 \\
\hline \multicolumn{4}{|l|}{ Pathological stage, $n$} \\
\hline Benign & 19 & 10 & 0.082 \\
\hline pT1a & 54 & 56 & 0.046 \\
\hline pT1b & 39 & 27 & \\
\hline pT2a & 11 & 11 & \\
\hline $\mathrm{pT} 2 \mathrm{~b}$ & 1 & 7 & \\
\hline рТЗа & 20 & 32 & \\
\hline pT4 & 0 & 2 & \\
\hline Metastatic & 5 & 6 & 1.000 \\
\hline \multicolumn{4}{|l|}{ Positive margin, $\mathrm{n}$} \\
\hline Radical nephrectomy & 0 & 0 & 1.000 \\
\hline Partial nephrectomy & 5 & 9 & 0.566 \\
\hline
\end{tabular}

Several groups have evaluated the impact of previous abdominal procedure on non-urological laparoscopic surgeries. In a recent study of more than 160000 patients, Seetahal et al concluded that previous open abdominal surgery increased the hospital LOS, complication rate, and OT in patients undergoing various subsequent laparoscopic general surgery. ${ }^{6}$ Previous abdominal surgery resulted in more access-related complications in laparoscopic gynecological procedure. ${ }^{7}$

To date, few studies evaluated the impact of previous abdominal surgery on urological laparoscopic procedures and most were early in the laparoscopic experience. ${ }^{12-16}$ Moreover, few patients included in those studies had a LPN or LRN. ${ }^{12-14}$ Seifman et al reported longer hospital stay (3.8 vs. 2.6 days; $p=0.002)$, OT ( 16 vs. $4 \% ; p=0.009$ ), and major complications ( 16 vs. $5 \% ; p=0.022$ ) in patients with previous surgery. ${ }^{12}$ This study included 190 patients who underwent upper tract standard and laparoscopic hand-assisted pro-

\begin{tabular}{|c|c|c|c|}
\hline Variable & $\begin{array}{c}\text { Past } \\
\text { abdominal } \\
\text { surgeries } \\
(n=146)\end{array}$ & $\begin{array}{c}\text { No } \\
\text { abdominal } \\
\text { surgery } \\
(n=147) \\
\end{array}$ & $\mathbf{p}$ \\
\hline Median EBL, mL (IQR) & $88(50-150)$ & $100(50-200)$ & 0.211 \\
\hline Operative time, $\min (\mathrm{SD})$ & $136(47)$ & $144(52)$ & 0.154 \\
\hline Warm ischemia time, $\min (\mathrm{SD})$ & $21.8(7.8)$ & $22.5(6.5)$ & 0.635 \\
\hline Open conversion, n (\%) & $3(2.1)$ & $2(1.4)$ & 0.684 \\
\hline Median LOS, days (IQR) & $4(3-5)$ & $3(3-4)$ & 0.001 \\
\hline \multicolumn{4}{|l|}{$\begin{array}{l}\text { Clavien grade complication, } \\
\mathrm{n}(\%)\end{array}$} \\
\hline 0 & $111(76.0)$ & $127(86.4)$ & 0.069 \\
\hline I-II & $26(17.8)$ & $16(10.9)$ & \\
\hline III-IVa & $9(6.2)$ & $4(2.7)$ & \\
\hline
\end{tabular}

cedures, including four cases of LPN and 18 cases of LRN. A study by Parsons et al of 700 cases of various laparoscopic procedures revealed similar perioperative outcomes in patients with and without previous abdominal surgery, except for a higher rate of transfusion in patients undergoing nephrectomy $(p<0.001)$ and pyeloplasty $(p=0.02) .{ }^{13}$ More recently, in a study of 79 cases of laparoscopic nephrectomy for non-functioning kidneys, patients with vs. without previous ipsilateral renal surgery experienced increased OT (98.6 vs. 62.3 minutes; $p=0.03$ ). ${ }^{15}$ Other operative data were similar between the two groups. Authors concluded that laparoscopic nephrectomy can be done safely in patients with a history of ipsilateral renal surgery, but recognize that their results may not be applicable to the setting of radical nephrectomy for malignant tumour. Aminsharifi also found no difference in the outcomes of laparoscopic simple nephrectomy in patients with a history of ipsilateral open vs. percutaneous surgery. ${ }^{17}$ Turna et al described their experience with transperitoneal and retroperitoneal LPN in 25 patients with previous ipsilateral renal procedures. ${ }^{16}$ Although no intraoperative complications occurred, even in experienced hands, such cases involved a long WIT of 35.8 minutes and OT of three hours.

In our study, patients with previous abdominal surgery were older. This could be explained by the fact that older patients are more likely throughout the years to have surgical indications. The proportion of females was also higher because of the incidence of gynecological procedures. Increased $\mathrm{CCl}$ is attributed to older age in patients with prior surgery and to the substantial proportion of prior oncological surgeries. We report similar perioperative outcomes in patients with previous abdominal surgery. In multivariate analysis, prior abdominal surgery was not associated with complication or with worse perioperative outcomes, defined as results inferior to the whole cohort's median (i.e., EBL $\geq 100 \mathrm{~mL}$, OT $\geq 135$ minutes, and LOS $\geq 4$ days). A possible 
Ouellet et al.

\begin{tabular}{|c|c|c|c|}
\hline Variables & Open cholecystectomy ( $n=19$ ) & No cholecystectomy ( $n=123$ ) & $\mathbf{p}$ \\
\hline Age, years (SD) & $67.5(11.7)$ & $63.8(12.9)$ & 0.239 \\
\hline Male, n (\%) & 7 (36.8) & $82(66.7)$ & 0.007 \\
\hline Charlson score (SD) & $4.1(2.5)$ & $2.8(1.9)$ & 0.016 \\
\hline BMI, $\mathrm{kg} / \mathrm{m}^{2}$ (SD) & $29.0(4.1)$ & $27.9(5.1)$ & 0.390 \\
\hline ASA, n (\%) & & & 0,915 \\
\hline 1 & $1(5.3)$ & $9(7.4)$ & \\
\hline 2 & $11(57.9)$ & $74(60.7)$ & \\
\hline 3 & $7(36.8)$ & $37(30.3)$ & \\
\hline 4 & $0(0)$ & $2(1.6)$ & \\
\hline Partial nephrectomy, n (\%) & 9 (42.9) & $38(30.9)$ & 0.318 \\
\hline Tumour size cm, (SD) & $4.1(1.8)$ & $5.1(3.0)$ & 0.044 \\
\hline Median EBL, mL (IQR) & $50(50-200)$ & $100(50-200)$ & 0.474 \\
\hline Operative time, $\min (\mathrm{SD})$ & $148(57)$ & $128(39)$ & 0.049 \\
\hline WIT, $\min (S D)$ & $25.9(4.7)$ & $21.9(7.2)$ & 0.152 \\
\hline Open conversion, n (\%) & $0(0)$ & $4(3.2)$ & 1.000 \\
\hline Median LOS, days (IQR) & $4(3.5-5.0)$ & $3(3.0-5.0)$ & 0.050 \\
\hline Clavien grade complication, $\mathrm{n}(\%)$ & & & 0.004 \\
\hline 0 & $11(58)$ & $103(84)$ & \\
\hline I-II & $4(21)$ & $17(14)$ & \\
\hline III-IVa & $4(21)$ & $3(2)$ & \\
\hline
\end{tabular}

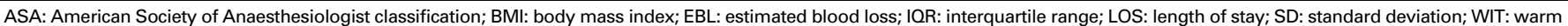
ischemia time.

explanation is that prior abdominal surgery was not necessarily in the same anatomic location as the LPN or LRN and adhesiolysis was sometimes very limited.

To assess the impact of previous surgery in the same anatomical site, we performed a subset analysis of patients with and without previous open cholecystectomy undergoing right LPN and LRN. Even if open cholecystectomy is now rarely performed, many patients in our cohort $(n=42)$ had this surgery performed in the last decade. Previous open cholecystectomy resulted in a 4.5-fold increased risk of complication and a longer LOS in patients undergoing right laparoscopic nephrectomy. This is likely attributed to the increased difficulty of laparoscopic surgery in previously operated anatomical site because of impaired visualisation due to adhesions, distorted tissue plane, difficult renal mobilization, and the need to perform more extensive adhesiolysis. Therefore, we believe that patients with a history of open cholecystectomy undergoing right LPN or LRN may be counselled about their increased risk of complications. Our results might also suggest that prior open surgery in the same anatomic location could results in an increased risk of complication. Longer LOS is likely a consequence of the higher complication rate. Our conclusions may not be applicable to patients with a history of laparoscopic cholecystectomy, as this results in less adhesion formation. ${ }^{18}$ We did not have enough laparoscopic cholecystectomy cases $(n=2)$ in those treated with right nephrectomy to perform a thorough analysis. Further studies are needed to answer that question.

Limitations of our study include its retrospective nature and the potentially missing data concerning previous abdominal surgery. Data-recording may contain errors, but it is very unlikely that any major abdominal surgery would not have been be noticed or recorded after several assessments, including complete history and physical examination. Sample size may also undermine the strength of our analysis; since most of the outcomes did not differ after statistical analysis, we wonder if the analysis was underpowered. However, in general our data does not show a clear and strong association between previous surgery and worse outcomes, therefore, if there is any association, it is likely weak.

\section{Conclusion}

Previous abdominal surgery was not associated with worse perioperative outcomes after transperitoneal LPN and LRN for renal masses. However, previous open cholecystectomy resulted in an increased risk of complication and longer LOS in patients undergoing right laparoscopic nephrectomy; those patients should be counselled about their increased surgical risk.

Competing interests: The authors report no competing personal or financial interests.

This paper has been peer-reviewed. 


\section{References}

1. Weibel MA, Maino G. Peritoneal adhesions and their relation to abdominal surgery. A postmortem study. Am J Surg 1973;126:345-53. https://doi.org/10.1016/50002-9610(73)80123-0

2. Liakakos T, Thomakos N, Fine PM, et al. Peritoneal adhesions: Etiology, pathophysiology, and clinical significance. Recent advances in prevention and management. Dig Surg 2001;18:260-73. https://doi.org/10.1159/000050149

3. Binenbaum SJ, Goldfarb MA. Inadvertent enterotomy in minimally invasive abdominal surgery. JSLS 2006;10:336-40.

4. Van Goor H. Consequences and complications of peritoneal adhesions. Colorectal Dis 2007;9:23-34. https://doi.org/10.1111/i.1463-1318.2007.01358.x

5. Ellis $\mathrm{H}$, Moran BJ, Thompson IN, et al. Adhesion-related hospital readmissions after abdominal and pelvic surgery: A retrospective cohort study. Lancet 1999;353:1476-80. https://doi.org/10.1016/ S0140-6736(98)09337-4

6. Seetahal $S$, Obirieze $A$, Cornwell EE, et al. Open abdominal surgery: a risk factor for future laparoscopic surgery? Am I Surg 2015;209:623-6. https://doi.org/10.1016/i.amisurg.2014.12.017

7. Lécuru F, Leonard F, Philippe Jais J, et al. Laparoscopy in patients with prior surgery: Results of the blind approach. JSLS 2001:5:13-6.

8. Rassweiler J, Rassweiler MC, Kenngott $\mathrm{H}$, et al. The past, present and future of minimally invasive therapy in urology: A review and speculative outlook. Minim Invasive Ther Allied Technol 2013; 22:200-9. https://doi.org/10.3109/13645706.2013.816323

9. Becker A, Pradel L, Kluth L, et al. Laparoscopic vs. open partial nephrectomy for clinical TI renal masses: No impact of surgical approach on perioperative complications and long-term postoperative quality of life. World J Urol 2015;33:421-6. https://doi.org/10.1007/s00345-014-1318-1

10. Laird A, Choy KC, Delaney H, et al. Matched pair analysis of laparoscopic vs. open radical nephrectomy for the treatment of $\mathrm{T3}$ renal cell carcinoma. World J Urol 2015;33:25-32. https://doi.org/10.1007/ s00345-014-1280-y
11. Bayrak 0 , Seckiner I, Erturhan $S$, et al. Comparison of the complications and the cost of open and laparoscopic radical nephrectomy in renal tumours larger than $7 \mathrm{~cm}$. Urol J 2014;11:1222-7.

12. Seifman BD, Dunn RL, Wolf SJ Jr. Transperitoneal laparoscopy into the previously operated abdomen: Effect on operative time, length of stay, and complications. J Urol 2003; 169:36-40. https://doi.org/10.1016/ S0022-5347(05)64029-3

13. Parsons JK, Jarrett TJ, Chow GK, et al. The effect of previous abdominal surgery on urological laparoscopy. J Urol 2002;168:2387-90. https://doi.org/10.1016/S0022-5347(05)64151-1

14. Pautler SE, Phillips IL, Walther MM. Assessment of risk for intra-abdominal adhesions at laparoscopy for urological tumours. J Urol 2002;168:2391-4. https://doi.org/10.1016/50022-5347(05)64152-3

15. Aminsharifi A, Taddayun A, Niroomand $R$, et al. Laparoscopic nephrectomy for non-functioning kidneys is feasible after previous ipsilateral renal surgery: A prospective cohort trial. J Urol 201 1;185:930-4. https://doi.org/10.1016/i.juro.2010.10.075

16. Turna $B$, Aron $M$, Frota $R$, et al. Feasibility of laparoscopic partial nephrectomy after previous ipsilateral renal procedures. Urology 2008;72:584-8. https://doi.org/10.1016/j.urology.2008.04.002

17. Aminsharifi A, Goshtasbi B. Laparoscopic simple nephrectomy after previous ipsilateral open vs. percutaneous renal surgery. JSLS 2012;16:592-6. https://doi.org/10.4293/108680812X13462882737212

18. Polymeneas $G$, Theodosopoulos $T$, Stamatiadis A, et al. A comparative study of postoperative adhesions formation after laparoscopic vs. open cholecystectomy. Surg Endosc 2001;15:41-3. https://doi.org/10.1007/s004640000269

Correspondence: Dr. Claudio Jeldres, Division of Urology, Departments of Surgery, Centre Hospitalier Universitaire de Sherbrooke, Université de Sherbrooke, Sherbrooke, QC, Canada; claudio.jeldres@usherbrooke.ca

\section{CUA Nominating Committee Request}

We are looking for dedicated individuals to fill the following positions on the CUA Board of Directors:

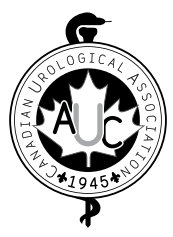

\section{CUA Vice President (one-year term) CUA Member at Large: British Columbia (three-year term)}

Please forward the names of potential candidates to Dr. Michael Leonard, Chair, Nominating Committee (mleonard@cheo.on.ca) by April 27, 2017.

If you are nominating someone, we ask that you include a few sentences as to why the nominee would be suitable for the position. Please be advised that self-nominations are accepted.

Only Active Members of CUA may serve on the Board of Directors.

While all individuals presented to the Nominating Committee will be carefully considered, not all of those suggested will appear on the slate of nominees. The Nominating Committee is charged with recommending a single individual for each position, if possible. As per the decision at last year's AGM, no further nominations will be accepted after the deadline, nor will nominations for officer positions be allowed from the floor of the AGM unless the individual(s) so nominated has been previously vetted by the Nominating Committee.

The CUA Annual General Meeting (AGM) will take place on Monday, June 26, 2017 from 4:30-6:00 pm in room Pier 4 of the Westin Harbour Castle Hotel, Toronto, ON. 